\title{
Structure-Reactivity Correlation of Photochemical Reactions in Organic Crystals: Intramolecular Hydrogen Abstraction in an Aromatic Nitro Compound
}

\author{
Kaillathe Padmanabhan, Kailasam Venkatesan, ${ }^{*}$ and Vaidyanathan Ramamurthy * \\ Department of Organic Chemistry, Indian Institute of Science, Bangalore-560 012, India \\ Rolf Schmidt and Dietrich Döpp * \\ F.B.6. Organische Chemie, Universitat Duisberg, D-4100, Duisberg 1, West Germany
}

The molecular structure of 1,4-bis-(2-chloro-1,1-dimethylethyl)-2-nitrobenzene has been determined by $X$-ray crystallography. The single-crystal $X$-ray investigation, $R=0.067$, showed the compound to be monoclinic, space group $P 2_{1}, a=6.388(2), b=13.848(4), c=8.578(3) \AA, \beta=94.05(3)^{\circ}$. Structural analysis of 2-nitro-t-butylbenzenes which undergo intramolecular hydrogen abstraction in the solid state upon irradiation by u.v. light was carried out in connection with structure-reactivity correlation studies and $X$-ray crystallographic investigations. On the basis of intramolecular geometry and molecular packing considerations, it has been possible to identify the hydrogen atom abstracted preferentially in crystals of this compound. The benzene ring is found to exist in the boat conformation.

2-Nitro-t-butylbenzenes (1) (Scheme 1) upon irradiation by u.v. light ( $>280 \mathrm{~nm}$ ) undergo intramolecular hydrogen abstraction leading to the indole 1 -oxides (2). ${ }^{1}$ Compounds (3)-(5) also react in a similar manner in solution as well as in the solid state. ${ }^{2}$

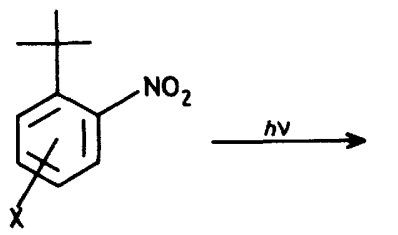

(1)
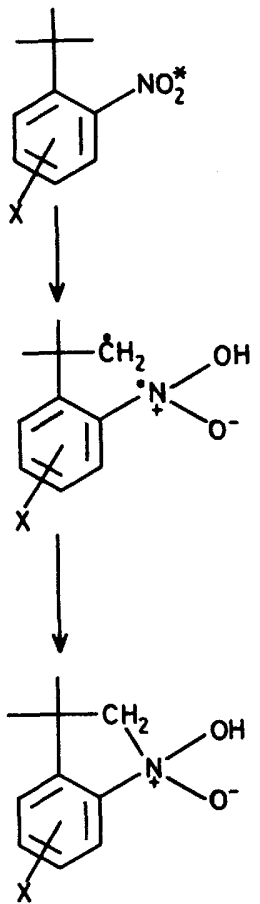

(2)<smiles>[X]c1c(C)c([N+](=O)[O-])c(C(C)(C)C)c([N+](=O)[O-])c1C</smiles>

(3) $\mathrm{X}=\mathrm{NO}_{2}$

(4) $\mathrm{X}=\mathrm{CH}_{3}$

(5) $\mathrm{X}=\mathrm{COCH}_{3}$
In our earlier paper, ${ }^{3} X$-ray structures of compounds (3)-(5) were reported, and this led to valuable information regarding the geometrical criteria (distances and directionality) for hydrogen abstraction by a nitro chromophore in these compounds. However, in the case of compounds (3)-(5), the conclusions derived from $X$-ray structural data are not verifiable by experiment, since all hydrogens are equivalent in the t-butyl group and also there are two nitro groups ortho to the t-butyl group. On the other hand, in 1,4-bis-(2-chloro-1,1-dimethylethyl)-2-nitrobenzene (6), a closely analogous molecule, there is only one nitro group ortho to the t-butyl group and also one of the substituents on the tertiary carbon is a $\mathrm{CH}_{2} \mathrm{Cl}$ group. This is expected to facilitate identification of the hydrogen being abstracted and substantiate the conclusion reached regarding the geometrical requirements for hydrogen abstraction by an $n, \pi^{*}$ excited nitro group from our earlier $X$-ray studies of compounds (3)-(5). With this in mind, we have examined the photochemical behaviour and $X$-ray structure of (6). Results of these studies are presented below.

\section{Results}

1,4-Bis-(2-chloro-1,1-dimethylethyl)-2-nitrobenzene (6) upon irradiation by u.v. light both in solution and in the solid state undergoes intramolecular hydrogen abstraction involving the nitro group and the adjacent $\mathrm{CH}_{2} \mathrm{Cl}$ group giving rise to the $3 \mathrm{H}$ indole 1-oxide (9) (Scheme 2). Because of thermal and photochemical instability, the $N$-oxide (9) could not be isolated. Instead, the hydroxamic acid (11) derived from the hydrate of (9) by dehydrohalogenation was obtained. In addition the lactam (12) was isolated (Scheme 3). Product ratios obtained under different reaction conditions are given in Table 1.

\section{Discussion}

Structure-Reactivity Correlation--For a hydrogen atom to be abstracted by the oxygen atom of a nitro group, the ideal geometry would be a short $\mathrm{O} \cdots \mathrm{H}$ distance (i.e. shorter than the van der Waals sum of $2.72 \AA$ ) with the $\mathrm{C}-\mathrm{H}$ bond in the plane of the nitro group and with $\mathrm{N}-\mathrm{O} \cdots \mathrm{H}=90^{\circ}$. This is because the abstraction involves an $n, \pi^{*}$ excited state in which the new O-H bond is formed using the half-occupied oxygen $n$-orbital. Deviations from the ideal geometry can be specified by angles $\Delta_{H}, \Delta_{O}$, and $\tau$ (Figure 1). $\Delta_{H}$ Is the

Scheme 1. 


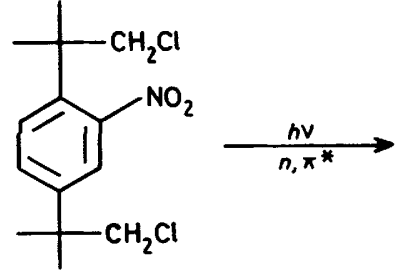

(6)

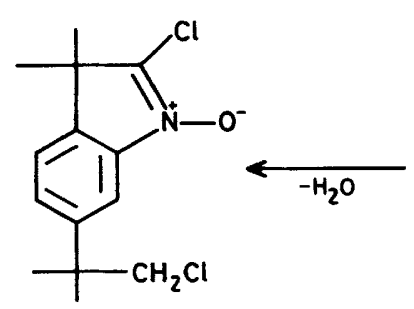

(9)

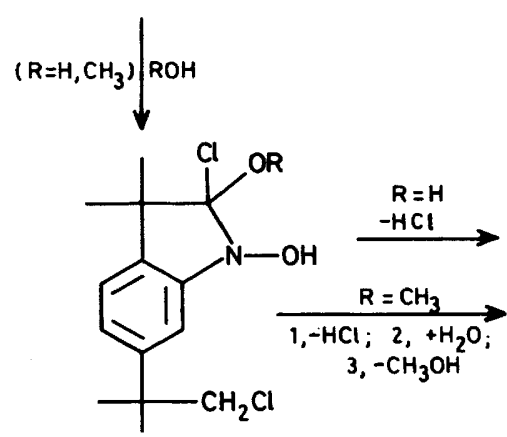

(10)

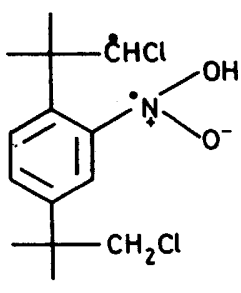

(7)

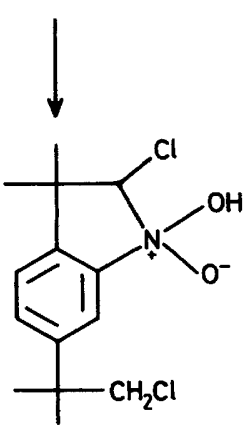

(8)

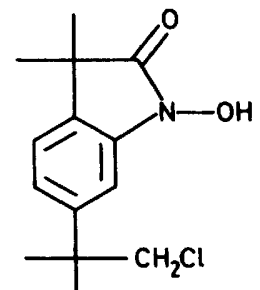

(11)

Scheme 2.

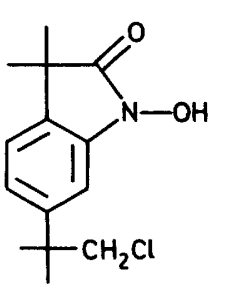

(11)

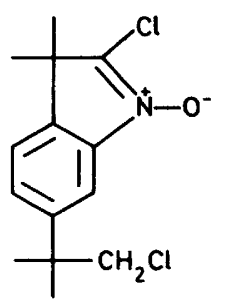

(9)

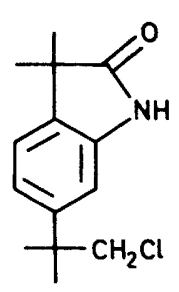

(12)<smiles>ClC1CCCCC1C1CCCC1</smiles>

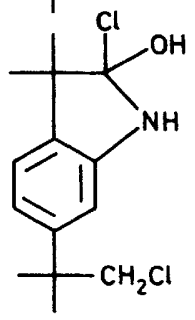

Scheme 3.

Table 1. Product distribution upon photolysis of (6)

Yield of product $(\%)$

Reaction medium

$\begin{array}{cc}(11) & (12) \\ 73 & 9 \\ 32 & 39 \\ 23 & 22 \\ 21 & 13\end{array}$

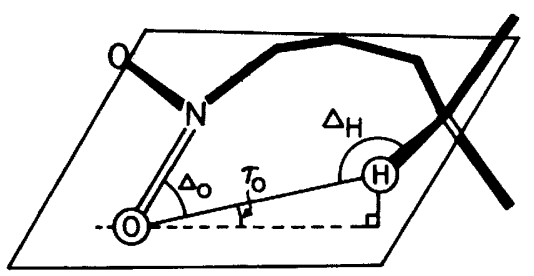

$$
\begin{array}{ll}
\text { Sum of van der Waals radii } & \begin{array}{l}
O+H=2.72 \AA \\
C+N=3.25 \AA
\end{array} \\
\text { Ideal } \tau_{O} \quad 0^{\circ} & \\
\text { Ideal } \Delta_{O} \quad 90^{\circ} & \\
\text { Ideal } \Delta_{H} \quad 180^{\circ} &
\end{array}
$$

Figure 1.

C-H ... O angle for which a linear geometry $\left(\Delta_{\mathrm{H}} 180^{\circ}\right)$ appears to be favoured in bimolecular hydrogen abstraction. ${ }^{4}$ $\Delta_{\mathrm{o}}$ Is the $\mathrm{N}-\mathrm{O} \cdots \mathrm{H}$ angle. The atomic orbital on oxygen involved in the abstraction process (the $n$-orbital) is largely $2 p$-like in character ${ }^{5}$ and hence the ideal value for $\Delta_{0}$ should be close to $90^{\circ} . \Delta_{H}$ Is the angle subtended by the $\mathrm{O} \cdot \mathrm{H}$ vector and its projection on the mean plane of the nitro group and should have an ideal value of $0^{\circ}$ for efficient hydrogen abstraction. $\Delta_{\mathrm{H}}=180^{\circ}, \Delta_{\mathrm{O}}=90^{\circ}, \tau=0^{\circ}$ imply that the optimal approach is at right angles to the $\mathrm{N}-\mathrm{O}$ bond and in the plane of the nitro group.

The intramolecular geometrical parameters $\mathrm{O} \cdots \mathrm{H}, \Delta_{\mathrm{H}}, \Delta_{\mathrm{O}}$, and $\tau$ are recorded in Table 2 for compound (6). The atomnumbering scheme is shown in Figure 2. On the basis of the intramolecular $\mathrm{O} \cdots \mathrm{H}$ distances in Table 2 , there could be three possibilities for hydrogen abstraction involving the nitro group and the chloro-t-butyl group in the ortho position. However, from a consideration of the geometrical parameters, namely $\Delta_{\mathrm{H}}, \Delta_{\mathrm{O}}$, and $\tau$ angles, it seems very reasonable to conclude that, in compound (6), the probable reaction is unique, namely, abstraction of $H(91)$ by $O(16)$ (Table 2). $\Delta_{H}$ For this possibility $\left(131.9^{\circ}\right)$ deviates very much from linear geometry (i.e. $180^{\circ}$ ), and this provides quantitative evidence for what has been qualitatively obvious for some time, namely that large deviations from the preferred linear approach may be tolerated in intramolecular photochemical hydrogen abstractions. ${ }^{4}$

The value of $\tau$, which is the $\mathrm{C}-\mathrm{N}-\mathrm{O} \ldots \mathrm{H}$ dihedral angle, is larger $\left(49.4^{\circ}\right)$ than the ideal value of $0^{\circ}$ for this unique choice. Wagner ${ }^{6}$ has pointed out that coplanar $\left(\tau 0^{\circ}\right)$ hydrogen abstraction is not a strict requirement for a Norrish Type II process for ketones which is also an intramolecular $n, \pi^{*}$ excited state reaction. Examples of such non-coplanar hydrogen abstractions have been reported recently by Ariel et $a l^{7}$ and Wagner et al. ${ }^{8}$ where the value of $\tau$ is in the range $40-50^{\circ}$. Further for an intramolecular reaction one would not expect to find the ideal value of $\tau 0^{\circ}$. 
Table 2. Intramolecular geometrical parameters relevant to hydrogen abstraction for compound (6). E.s.d.s are given in parentheses

\begin{tabular}{cccrrr}
\multicolumn{1}{c}{ Atom pair } & $\mathrm{O} \cdots \mathrm{H}(\AA)$ & $\Delta_{\mathrm{H}}\left({ }^{\circ}\right)$ & \multicolumn{1}{c}{$\Delta_{\mathrm{O}}\left({ }^{\circ}\right)$} & \multicolumn{1}{c}{$\left(^{\circ}\right)$} & $\Delta_{\mathrm{N}}\left({ }^{\circ}\right)^{*}$ \\
$\mathrm{O}(16) \cdots \mathrm{H}(91)$ & $2.11(5)$ & $131.9(29)$ & $117.5(12)$ & $49.4(15)$ & $97.1(110.6)$ \\
$\mathrm{O}(16) \cdots \mathrm{H}(101)$ & $2.46(3)$ & $125.8(26)$ & $67.7(9)$ & $92.5(11)$ & $65.9(57.0)$ \\
$\mathrm{O}(17) \cdots \mathrm{H}(101)$ & $2.73(4)$ & $137.8(26)$ & $56.2(9)$ & $-100.5(11)$ & $62.4(49.0)$
\end{tabular}

$\mathrm{C}(9) \ldots \mathrm{N}(15) 3.475(12) \AA ; \mathrm{C}(10) \cdots \mathrm{N}(15) 2.997(12) \AA$.

Ideal values: $\Delta_{\mathrm{H}}=180^{\circ} ; \Delta_{\mathrm{O}}=90^{\circ} ; \tau=0^{\circ} ; \Delta_{\mathrm{N}}=180^{\circ}$.

* The values outside parentheses correspond to $\mathrm{N}-\mathrm{O} \cdots \mathrm{HYP}=90^{\circ}$ and those inside to $\mathrm{N}-\mathrm{O} \cdots \mathrm{HYP}=120^{\circ}$.

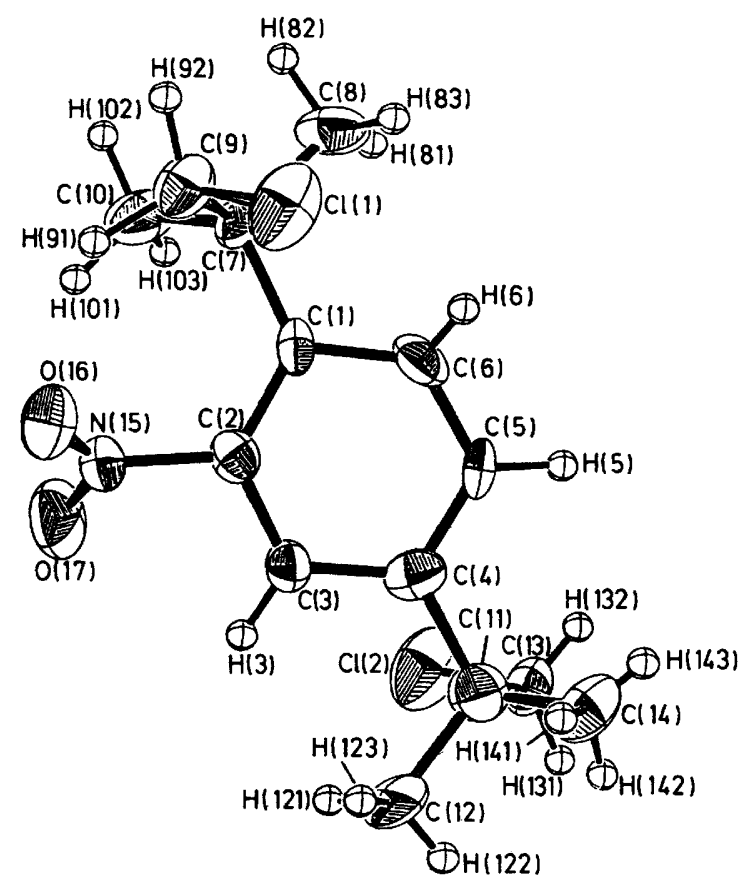

Figure 2. ORTEP plot of compound (6) with the atom-numbering scheme and thermal ellipsoids at the $50 \%$ probability level. The hydrogen atoms are represented by spheres of arbitrary size

Additional evidence for the choice of the unique possibility comes from the following analysis. Hypothetical points (represented by HYP) were fixed in the direction of the $n$-orbitals of the nitro group at $90^{\circ}\left(\mathrm{N}-\mathrm{O} \cdots \mathrm{HYP}=90^{\circ}\right)$ at a distance of $1 \AA$ from the two oxygen atoms of the nitro group. For a hydrogen atom to be abstracted by an $n, \pi^{*}$ excited nitro group, the best condition would be collinearity of $\mathrm{O}, \mathrm{HYP}$, and H, i.e. an ideal value of $180^{\circ}$ for the $\mathrm{O} \cdots$ HYP $\ldots$ H angle $\left(\Delta_{N}\right)$ and the values calculated are recorded in Table 2. Even though the value of $\Delta_{\mathrm{N}}$ deviates from collinearity for the unique choice $\left(97.1^{\circ}\right)$ the deviation is even more for the other two possibilities. Assuming that the $n$-orbitals are oriented at $120^{\circ}$ instead of $90^{\circ}$, the angles $\Delta_{\mathrm{N}}$ were recalculated with $\mathrm{N}-\mathrm{O} \cdots \mathrm{HYP} 120^{\circ}$. The values of $\Delta_{N}$ for this case are given in parentheses in Table 2. The results obtained are substantially the same as for the $90^{\circ}$ calculation.

The next step in the reaction is cyclization involving $\mathrm{C}(9)$ and $N(15)$ radical centres. The distance between these atoms which is as large as $3.475 \AA$ may not allow cyclization. Consequently, for the above reaction to occur, the t-butyl group of the biradical intermediate after primary hydrogen abstraction has to undergo rotation about the $\mathrm{C}(1)-\mathrm{C}(7)$ bond in one direction to bring $C(9)$ nearer to $N(15)$ for cyclization. We do not know whether such rotation is allowed for the biradical by the crystal lattice constraints because there is one example of a photogenerated biradical which has enough freedom to rotate and
Table 3. Fractional atomic co-ordinates $\left(\times 10^{4}\right)$ for non-hydrogen atoms in compound (6) with their e.s.d.s in parentheses

\begin{tabular}{lrrr} 
Atom & $x$ & \multicolumn{1}{c}{$y$} & $z$ \\
$\mathrm{C}(1)$ & $1263(11)$ & $-199(6)$ & $1533(7)$ \\
$\mathrm{C}(2)$ & $2577(11)$ & $487(6)$ & $889(8)$ \\
$\mathrm{C}(3)$ & $3953(11)$ & $1089(6)$ & $1732(8)$ \\
$\mathrm{C}(4)$ & $4211(12)$ & $994(6)$ & $3366(9)$ \\
$\mathrm{C}(5)$ & $2969(13)$ & $325(7)$ & $4038(8)$ \\
$\mathrm{C}(6)$ & $1497(14)$ & $-208(7)$ & $3145(9)$ \\
$\mathrm{C}(7)$ & $-470(12)$ & $-783(6)$ & $608(8)$ \\
$\mathrm{C}(8)$ & $-2001(13)$ & $-1179(7)$ & $1760(12)$ \\
$\mathrm{C}(9)$ & $435(14)$ & $-1640(7)$ & $-226(10)$ \\
$\mathrm{C}(10)$ & $-1723(15)$ & $-174(8)$ & $-610(12)$ \\
$\mathrm{C}(11)$ & $5745(13)$ & $1641(8)$ & $4340(9)$ \\
$\mathrm{C}(12)$ & $7268(17)$ & $2196(9)$ & $3385(11)$ \\
$\mathrm{C}(13)$ & $4482(13)$ & $2355(7)$ & $5259(9)$ \\
$\mathrm{C}(14)$ & $6966(14)$ & $1031(8)$ & $5586(11)$ \\
$\mathrm{N}(15)$ & $2612(10)$ & $616(5)$ & $-842(7)$ \\
$\mathrm{O}(16)$ & $2963(10)$ & $-80(6)$ & $-1640(7)$ \\
$\mathrm{O}(17)$ & $2490(12)$ & $1424(6)$ & $-1330(7)$ \\
$\mathrm{Cl}(1)$ & $2245(4)$ & $-2358(2)$ & $934(3)$ \\
$\mathrm{Cl}(2)$ & $2882(5)$ & $3159(0)$ & $4065(3)$ \\
\hline
\end{tabular}

Table 4. Least-squares planes and the deviations $(\AA)$ of individual atoms for compound (6). E.s.d.s are given in parentheses

Plane I

$\begin{array}{lrlr}\mathrm{C}(1) & 0.012(8) & \mathrm{C}(7) & -0.118(8)^{*} \\ \mathrm{C}(2) & 0.016(8) & \mathrm{C}(11) & -0.015(10)^{*} \\ \mathrm{C}(3) & -0.026(8) & \mathrm{N}(15) & 0.088(7)^{*} \\ \mathrm{C}(4) & 0.012(8) & & \\ \mathrm{C}(5) & 0.022(9) & & \\ \mathrm{C}(6) & -0.041(9) & & \end{array}$

Plane II

$\begin{array}{llll}\mathrm{N}(15) & 0.000(6) & \mathrm{O}(16) & -0.000(16)\end{array}$

$\mathrm{O}(17) \quad-0.000(8)$

Equations of the planes

I $\quad 4.5573 X-9.6532 Y-1.0444 Z-0.5958=0$

II $-6.1903 X-1.6893 Y-1.2494 Z+1.6158=0$

Angle between planes I and II $53.8^{\circ}$

* Atoms not included in the plane.

form a product in the crystal ${ }^{7}$ and one example of one which cannot. ${ }^{9}$ In this context, it is worth mentioning that there is already a flexibility associated with this group by way of a nonrigid libration about the $\mathrm{C}(1)-\mathrm{C}(7)$ vector having amplitude of 4.1(17) $)^{\circ}$. This was done using the thermal motion analysis program THMB due to Trueblood. ${ }^{10}$ Rotation of the t-butyl group by $-10^{\circ}$ was found to be sufficient for cyclization of the biradical. The shortest intermolecular contact developed on rotation by $10^{\circ}$ was a $\mathrm{Cl} \cdots \mathrm{H}$ contact of $3.02 \AA$ which is not of consequence (van der Waals sum of $\mathrm{Cl}$ and $\mathrm{H} 2.95 \AA$ ).

On the basis of these observations, it can be concluded that the most probable reaction in the crystals of compound (6) is abstraction of $\mathrm{H}(91)$ by $\mathrm{O}(16)$ followed by cyclization between 
Table 5. Selected torsion angles $\left({ }^{\circ}\right)$ for compound (6). E.s.d.s are given in parentheses

$\begin{array}{lc}C(6)-C(1)-C(2)-C(3) & 0.1(11) \\ C(1)-C(2)-C(3)-C(4) & 4.2(12) \\ C(2)-C(3)-C(4)-C(5) & -3.2(11) \\ C(3)-C(4)-C(5)-C(6) & -1.7(12) \\ C(4)-C(5)-C(6)-C(1) & 6.6(14) \\ C(2)-C(1)-C(6)-C(5) & -5.4(12) \\ C(2)-C(1)-C(7)-C(8) & -161.0(7) \\ C(2)-C(1)-C(7)-C(9) & 80.3(9) \\ C(2)-C(1)-C(7)-C(10) & -41.3(10) \\ C(5)-C(4)-C(11)-C(12) & 169.0(8) \\ C(5)-C(4)-C(11)-C(13) & -68.7(10) \\ C(5)-C(4)-C(11)-C(14) & 45.3(11) \\ C(1)-C(2)-N(15)-O(16) & -55.2(10) \\ C(1)-C(2)-N(15)-O(17) & 131.9(8) \\ C(1)-C(7)-C(9)-C l(1) & 47.6(8) \\ C(4)-C(11)-C(13)-C l(2) & -62.7(8)\end{array}$

Table 6. Contacts between the chlorine atoms and the benzene ring atoms $(\AA)$ for compound (6). E.s.d.s are given in parentheses

$\begin{array}{cc}\text { Contact } & \text { Distance }(\AA) \\ \mathrm{Cl}(1) \cdots C(1) & 3.105(9) \\ \mathrm{Cl}(1) \cdots C(6) & 3.580(10) \\ \mathrm{Cl}(1) \cdots \mathrm{C}(2) & 3.946(9) \\ \mathrm{Cl}(1) \cdots \mathrm{C}(5) & 4.575(9) \\ \mathrm{Cl}(1) \cdots \mathrm{C}(3) & 4.933(9) \\ \mathrm{Cl}(1) \cdots \mathrm{C}(4) & 5.206(9) \\ \mathrm{Cl}(2) \cdots \mathrm{C}(4) & 3.185(8) \\ \mathrm{Cl}(2) \cdots \mathrm{C}(3) & 3.589(8) \\ \mathrm{Cl}(2) \cdots \mathrm{C}(5) & 3.925(10) \\ \mathrm{Cl}(2) \cdots \mathrm{C}(2) & 4.591(8) \\ \mathrm{Cl}(2) \cdots \mathrm{C}(6) & 4.801(10) \\ \mathrm{Cl}(2) \cdots \mathrm{C}(1) & 5.205(8)\end{array}$

$\mathrm{C}(9)$ and $\mathrm{N}(15)$ radicals to give the $3 H$-indole 1-oxide (9) (Scheme 2).

Molecular Geometry.-The final positional parameters are given in Table 3. The bond lengths and angles involving the nonhydrogen atoms are shown in Figure 3. The least-squares planes are given in Table 4 and some selected torsion angles in Table 5 .

The benzene ring is not planar, the maximum deviation of C(6) from the plane through the ring being $0.041(9) \AA$. The nitrogen atom of the nitro group deviates by $0.088(7) \AA$ in a direction opposite to that of $\mathrm{C}(7)$ to relieve steric strain (Table 4).

Inspection of the relevant torsion angles (Table 5) revealed that the conformation of the benzene ring tends to acquire approximately a boat shape with $C(3)$ and $C(6)$ as the bowsprits. Pulay et al. ${ }^{11}$ calculated that the force constant to bend benzene into a boat form [ $f$ (boat) $\left.0.4105 \mathrm{aJ} \mathrm{rad}^{-1}\right]$ is smaller than that to bend it into a chair form $\left[f\right.$ (chair) $\left.0.4894 \mathrm{aJ} \mathrm{rad}^{-1}\right]$. Therefore, if severe crowding forces a benzene ring into a nonplanar conformation, the distortion would rather be towards a boat than a chair form. Another example of a boat conformation for the benzene ring has been reported by van Havore et al. ${ }^{12}$ in a 4-t-butyl-3,5-dinitroanisole, with $\mathrm{C}(1)$ and $\mathrm{C}(4)$ as the bowsprits. Figure 4 compares the torsion angles inside the benzene ring of compound (6) with those of 4-t-butyl3,5-dinitroanisole. Apart from these examples, nonplanar geometries of simple aromatic rings have been reported only for pyridine derivatives. ${ }^{13}$ The abnormal valence angles at $\mathbf{C}(1)$, $C(2), C(4)$, and $C(6)$ are due to the bulky substituents. The large valence angle $\mathrm{C}(1)-\mathrm{C}(2)-\mathrm{C}(3)$ may also be attributed to the substituent nitro group at $C(2) .{ }^{14}$ Relief of steric strain is also

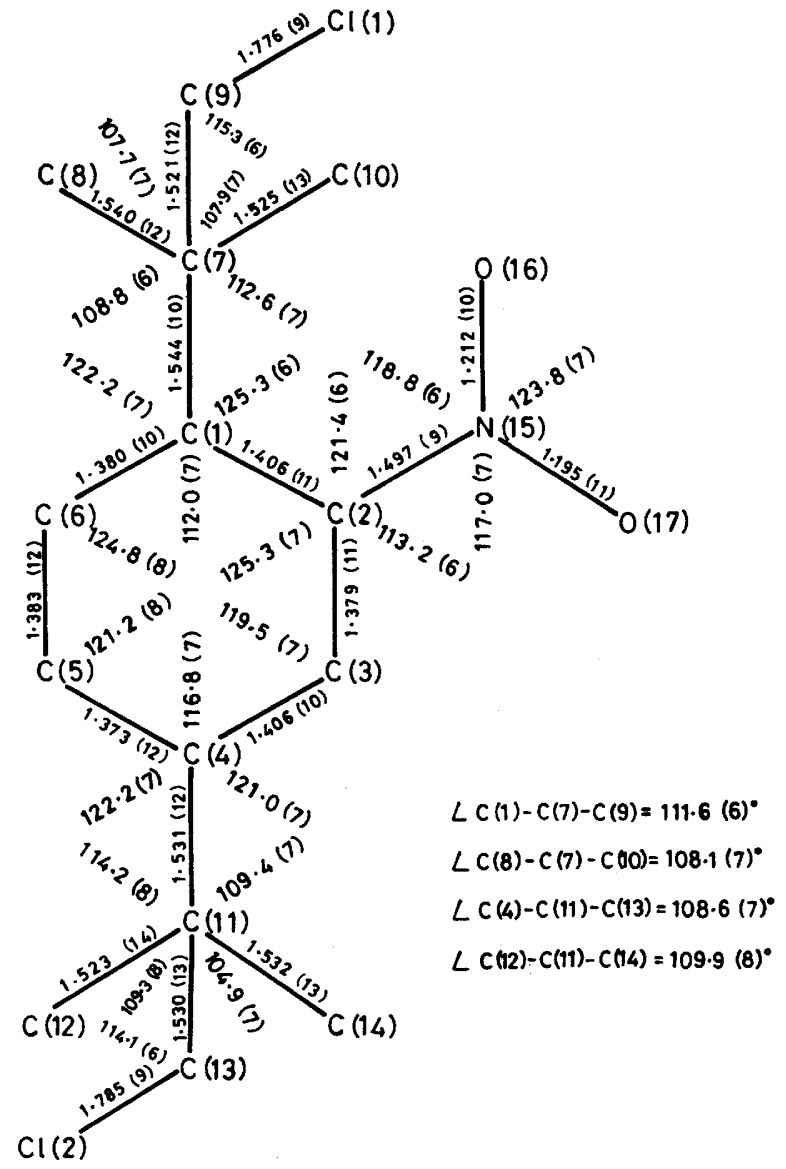

Figure 3. Bond lengths $(\AA)$ and angles $\left({ }^{\circ}\right)$ of the non-hydrogen atoms of compound (6) with e.s.d.s in parentheses

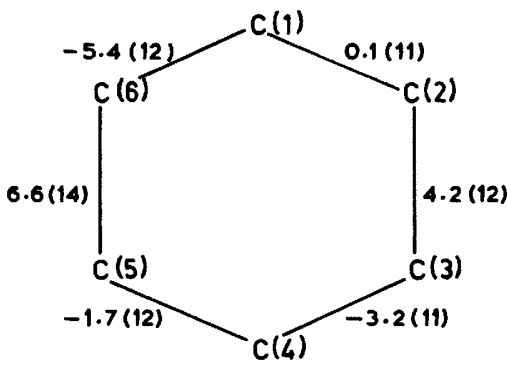

(a)

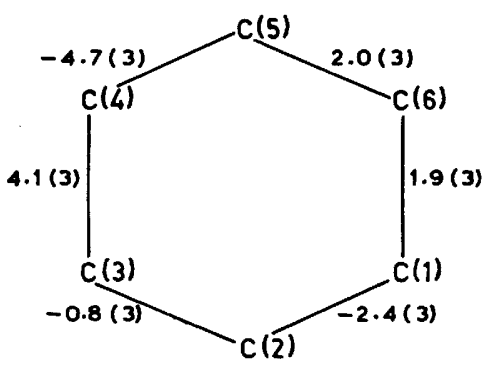

(b)

Figure 4. Torsional angles $\left({ }^{\circ}\right)$ inside the benzene ring with e.s.d.s in parentheses: (a) compound (6), (b) 4-butyl-3,5-dinitroanisole

achieved by rotating the nitro group over an angle of $53.8^{\circ}$ from the plane through the benzene ring.

Although significant only at about the $2 \sigma$ level the slight lengthening of the $C(2)-N(15)$ bond compared with the standard 

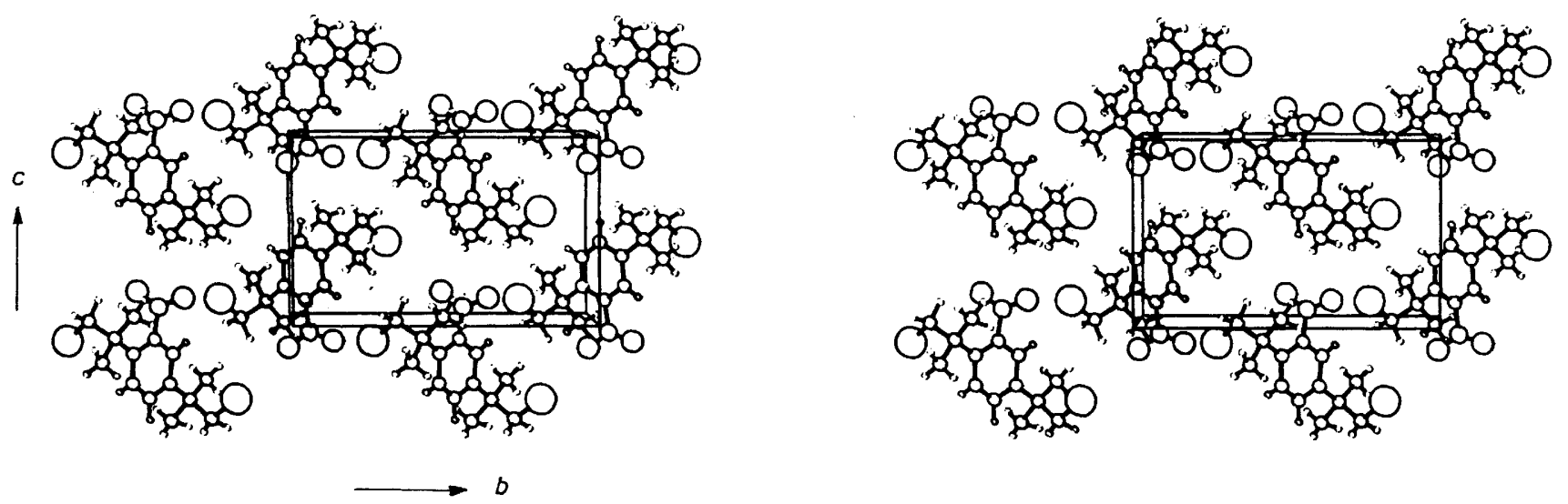

Figure 5. Stereoscopic diagram of the packing of the molecules in the crystal structure of compound (6) viewed along the $a$-axis

value of $1.475(10) \AA^{15,16}$ as well as the asymmetry in the exocyclic angles at $\mathrm{C}(2)$ and the widening of the angle $\mathrm{C}(7)$ $\mathrm{C}(1)-\mathrm{C}(2)$ may be due to steric crowding due to the presence of the chloro-t-butyl group.

A close examination of the intramolecular geometry (Table 6) showed that each of the chlorine atoms make an intramolecular short contact with one of the ring atoms, which is far less than the van der Waals sum. The distribution of these contacts follows a nearly centrosymmetric pattern, with $\mathrm{Cl}(1)$ pointing towards the $\mathrm{C}(1)-\mathrm{C}(6)$ bond and $\mathrm{Cl}(2)$ towards the $\mathrm{C}(4)-\mathrm{C}(3)$ bond. The torsion angles $\mathrm{C}(1)-\mathrm{C}(7)-\mathrm{C}(9)-\mathrm{Cl}(1)$ and $\mathrm{C}(4)-\mathrm{C}(11)-\mathrm{C}(13)-\mathrm{Cl}(2)$ are respectively $47.6(8)$ and $-62.7(8)^{\circ}$.

It is known that the chlorine molecule forms a crystalline complex with benzene ${ }^{17}$ in which the benzene molecules alternate in infinite chains, with the axis of the halogen molecule perpendicular to the planes of the two neighbouring benzene rings. This complex formation was interpreted as a charge-transfer interaction between benzene and chlorine. The presence of charge-transfer is confirmed by the fact that the distance between the neighbouring halogen atom and the plane of the benzene ring ( $3.28 \AA$ ) is much shorter than the van der Waals sum of $3.52 \AA$, between carbon and chlorine. ${ }^{17}$ Different geometries have been proposed for the benzene-chlorine complex. A recent CNDO study ${ }^{18}$ showed that an oblique geometry in which the chlorine molecule with the bond axis perpendicular to the benzene ring and centred over a $\mathrm{C}-\mathrm{C}$ bond has a more stable CNDO binding energy than those obtained for other geometrical models.

The observed intramolecular $\mathrm{C} \ldots \mathrm{Cl}$ distance suggests the possibility of a certain amount of charge-transfer interaction between the $\mathrm{C}-\mathrm{Cl}$ bonds and the benzene ring in compound (6). The short $\mathrm{C}(9) \cdots \mathrm{O}(16)$ intermolecular distance of $3.004 \AA$ could be due to a dipole-dipole interaction between $O(16)$ and $\mathrm{C}(9)$, the latter being activated by the electronegative chlorine atom.

The crystal structure is stabilized mainly by van der Waals interactions. A packing diagram of the molecules in the crystal lattice is illustrated in Figure 5.

\section{Experimental}

1,4-Bis-(2-chloro-1,1-dimethylethyl)-2-nitrobenzene (6).-A three-necked flask $(100 \mathrm{ml})$, equipped with a dropping funnel, a thermometer, and a reflux condenser was charged with glacial acetic acid $(36 \mathrm{ml})$ and acetic anhydride $(29 \mathrm{ml})$. To this were added, with magnetic stirring, anhydrous nitric acid $(8.1 \mathrm{ml}, 0.2$ mol). While a temperature between 33 and $35^{\circ} \mathrm{C}$ was maintained, finely powered 1,4-bis-(2-chloro-1,1-dimethylethyl)benzene $(20.0 \mathrm{~g}, 0.078 \mathrm{~mol}),{ }^{19}$ m.p. $53-54{ }^{\circ} \mathrm{C}$, was added in small portions. Hereafter the mixture was warmed to $50^{\circ} \mathrm{C}$ and stirred at this temperature for $2 \mathrm{~h}$. The resulting red-brown solution was poured on ice $(100 \mathrm{~g}$, the oily product taken up in benzene, and the benzene layer washed free of acid. The viscous residue formed crystals upon overnight storage at $4{ }^{\circ} \mathrm{C}$, which were washed with a little cold light petroleum and crystallized from methanol to give product $(9.6 \mathrm{~g}, 41 \%)$, m.p. $59-61{ }^{\circ} \mathrm{C}$; $v_{\max }(\mathrm{KBr}) 1525$ and $1360 \mathrm{~cm}^{-1}\left(\mathrm{NO}_{2}\right) ; \delta_{\mathrm{H}}\left(\mathrm{CDCl}_{3} ; \mathrm{Me}_{4} \mathrm{Si}\right) 1.42$ and 1.48 (two s, $6 \mathrm{H}$ each, $\mathrm{Me}_{2} \mathrm{C}$ ), 3.62 and 3.82 (two s, $2 \mathrm{H}$ each, $\mathrm{CH}_{2} \mathrm{Cl}$ ), and 7.25-7.63 (3 H, aryl) (Calc. for $\mathrm{C}_{14} \mathrm{H}_{19} \mathrm{Cl}_{2} \mathrm{NO}_{2}$ : C, 55.3; H, 6.25; N, 4.6; Cl, 23.3. Found: C, 55.1; H, 6.4; N, 4.5; Cl, $22.7 \%) ; \lambda_{\max }\left(\mathrm{CH}_{3} \mathrm{OH}\right) 340 \mathrm{pl}(\log \varepsilon 2.55)$ and $256 \mathrm{sh} \mathrm{nm}(3.2)$.

Irradiation of Compound (6).--(a) In methanol solution. A sample $(500 \mathrm{mg}, 1.65 \mathrm{mmol})$ in methanol $(100 \mathrm{ml})$ was placed in a reactor fitted with a water-cooled Duran $(>280 \mathrm{~nm})$ immersion well and a $150 \mathrm{~W}$ high-pressure mercury burner, purged with high-purity nitrogen for $30 \mathrm{~min}$ and irradiated for $4 \mathrm{~h}$ with continuous stirring and purging. The solution, initially colourless, assumed a dark red colour. The solution was concentrated and the dark red viscous residue was chromatographed on four plates $(20 \mathrm{~cm}$ high; $48 \mathrm{~cm}$ wide; covered with a $1 \mathrm{~mm}$ thick layer of silica gel Merek $60 \mathrm{PF}_{254}$ ) using 1:1 toluene-ethyl acetate for developing. Zones detected by quenching of the indicator fluorescence were eluted with acetone. The fastest zone $\left(R_{\mathrm{F}}\right.$ $0.69)$ gave $(6)(30 \mathrm{mg})$. From a narrow zone $\left(R_{\mathrm{F}} 0.31\right),(12)$ $\left(35 \mathrm{mg}, 9 \%\right.$ ), m.p. $175^{\circ} \mathrm{C}$ (from dichloromethane-hexane and cyclohexane) was obtained. The material from the broad main zone (averaged $R_{\mathrm{F}} c a .0 .19$ ) gave, after subsequent crystallizations from methanol-water and hexane, (11) (302 mg, 73\%), m.p. $160^{\circ} \mathrm{C}$

An integral quantum yield for formation of (11) from (6) using the isolated $366 \mathrm{~nm}$ line from a super-pressure mercury burner and standard ferrioxalate actinometry ${ }^{20}$ was determined to be $(3.3 \pm 0.5) \times 10^{-2} \mathrm{mmol} \mathrm{mEinstein}^{-1}$.

(b) In benzene solution. The same procedure was followed using (6) $(500 \mathrm{mg}, 1.65 \mathrm{mmol})$ benzene $(100 \mathrm{ml})$, irradiation time $6 \mathrm{~h}$. Upon work-up as described before, (6) (54 mg), (12) (144 $\mathrm{mg}, 39 \%$ ), and (11) (126 mg, 32\%) were obtained.

(c) As crystalline powder at $20-25^{\circ} \mathrm{C}$. Finely powdered (6) $(10.0 \mathrm{~g}, 32.9 \mathrm{mmol})$ were spread on a tin plate $(40 \times 55 \mathrm{~cm})$ and irradiated for three $30 \mathrm{~min}$ periods with the Duran-filtered light of a water-cooled $150 \mathrm{~W}$ high-pressure mercury burner (mounted $50 \mathrm{~cm}$ above the plate) through a sheet of cellophane to reduce undue losses by sublimation and convection. After the first and second $30 \mathrm{~min}$ period, the material was freshly powdered and redistributed on the plate. During the irradiation, the initially powder turned into a yellow sticky mass, of which $9.41 \mathrm{~g}$ were recovered. Chromatography on a column of 
silica gel slurry packed with toluene (particle size $0.2-0.5 \mathrm{~mm}$, height $15 \mathrm{~cm}$, diameter $4 \mathrm{~cm}$ ), and elution with toluene gave (6) $(8.91 \mathrm{~g})(89.1 \%$ recovery). Using toluene-ethyl acetate $9: 1$, lactam (12) $(200 \mathrm{mg}, 22 \%)$, m.p. $174{ }^{\circ} \mathrm{C}$ (from chloroform-nhexane), and using toluene-ethyl acetate 5:1 gradually going to $1: 1$, compound (11) $\left(220 \mathrm{mg}, 23 \%\right.$ ), m.p. $158-160^{\circ} \mathrm{C}$ (from chloroform-hexane) were obtained.

(d) As crystalline powder at $0-5{ }^{\circ} \mathrm{C}$ under argon. A sample $(10.0 \mathrm{~g})$ of finely powdered (6) was spread on the bottom of a Petri dish (diameter $20 \mathrm{~cm}$ ). This was stored inside a polyethylene glove bag under argon and kept on a cold plate $\left(0-5{ }^{\circ} \mathrm{C}\right)$ for irradiation for $2.5 \mathrm{~h}$ by the mercury lamp as before (mounted $20 \mathrm{~cm}$ over the dish outside the glove bag). During this time, gaseous hydrogen chloride accumulated inside the bag. The yellow sticky photolysate $(9.3 \mathrm{~g})$ was subjected to silica gel chromatography as before to yield $(6)(8.82 \mathrm{~g}, 88 \%$ recovery), (12) $(130 \mathrm{mg}, 13 \%)$, and (11) (220 mg, 21\%).

It should be noted that yields of products refer to starting material. Mechanical losses of starting material, which cannot be avoided in the procedures used, cause apparently lower yields.

6-(2-Chloro-1,1-dimethylethyl)-3,3-dimethyl-1-hydroxyindolin-2-one $(11)$.- - This had $v_{\text {max }},(\mathrm{KBr}) 3300-3060$ (br, $\mathrm{OH}), 1685(\mathrm{C}-\mathrm{O})$, and $1625 \mathrm{~cm}^{-1} ; \delta\left(\mathrm{CDCl}_{3} ; \mathrm{Me}_{4} \mathrm{Si}\right) 1.35$ and 1.48 (two s, $6 \mathrm{H}$ each, $\mathrm{Me}_{2} \mathrm{C}$ ), $3.70\left(6,2 \mathrm{H}, \mathrm{CH}_{2} \mathrm{Cl}\right.$ ), 7.07-7.40 (m, $3 \mathrm{H}$, aryl), and 10.75 (br, $1 \mathrm{H}, \mathrm{OH}) ; m / e(70 \mathrm{eV}$; e.i. -m.s.) 269 $\left(37 \%, M^{+}\right)$and $267\left(100, M^{+}\right)$and $251\left(28 \%, M^{+}-16\right)$ (Calc. for $\mathrm{C}_{14} \mathrm{H}_{18} \mathrm{ClNO}_{2}: \mathrm{C}, 62.8 ; \mathrm{H}, 6.7 ; \mathrm{N}, 5.2 ; \mathrm{Cl}, 13.25$. Found: $\mathrm{C}$, $62.9 ; \mathrm{H}, 6.8 ; \mathrm{N}, 5.2 ; \mathrm{Cl}, 13.5 \%$ ).

6-(2-Chloro-1,1-dimethylethyl)-3,3-dimethylindoline-2-one (12). - This had $v_{\text {max. }}(\mathrm{KBr}) 3200-3050$ (br, NH) and 1710 $\mathrm{cm}^{-1}(\mathrm{C}=\mathrm{O}) ; \delta\left(\mathrm{CDCl}_{3} ; \mathrm{Me}_{4} \mathrm{Si}\right) 1.43(12 \mathrm{H}), 3.63(\mathrm{~s}, 2 \mathrm{H}$, $\left.\mathrm{CH}_{2} \mathrm{Cl}\right), 7.00-7.30(\mathrm{~m}, 3 \mathrm{H}$, aryl $)$, and $9.1(1 \mathrm{H}, \mathrm{NH}) ; \mathrm{m} / \mathrm{e}(70 \mathrm{eV}$; e.i.-m.s.) $253\left(9 \%, M^{+}\right)$and $251\left(31, M^{+}\right), 236(12), 215(23$, $\left.M^{+}-\mathrm{HCl}\right)$, and $202\left(100, M^{+}-\mathrm{CH}_{2} \mathrm{Cl}\right)\left(\mathrm{Calc}\right.$. for $\mathrm{C}_{14} \mathrm{H}_{18^{-}}$ CINO: C, $66.8 ; \mathrm{H}, 7.2 ; \mathrm{N}, 5.6 ; \mathrm{Cl}, 14.1$. Found: $\mathrm{C}, 66.4 ; \mathrm{H}, 7.1 ; \mathrm{N}$, $5.6 ; \mathrm{Cl}, 14.8 \%$ ).

Crystallographic Measurements.--Single crystals of compound (6) were obtained from benzene-methanol. Intensity data were collected on an Enraf-Nonius CAD-4 diffractometer using graphite-monochromatized Mo- $K_{\alpha} \quad(\lambda=0.7107 \AA)$ radiation in the $\omega-2 \theta$ made with a scan speed of $1^{\circ} \min ^{-1}$ up to $\theta \leqslant 25^{\circ}$.

The stability and orientation of the crystal were monitored by measuring three standard reflections after every $2000 \mathrm{~s}$ data collection; the orientation was checked after every 200 reflections. The three monitored standard reflections $(\overline{1} \overline{2} 0, \overline{1} \overline{3} 1$, and $\overline{1} 30$ ) showed only statistical fluctuations. Out of a total of 1624 reflections collected, only 1104 were considered significant, $\left|F_{0}\right| \geqslant 2.06\left|F_{0}\right|$. The cell parameters were determined accurately by the least-squares analysis of 20 centred reflections in the range $10^{\circ}<\theta<18^{\circ}$. Corrections were applied for Lorentz and polarization factors but not for absorption.

Structure Analysis.-The structure was solved using the direct method program MULTAN 80. ${ }^{21}$ Isotropic refinement followed by anisotropic least-squares refinement of the nonhydrogen atoms converged to an $R$ value of 0.09 . Hydrogen atoms were located from a difference Fourier map at stereochemically reasonable positions. Full-matrix refinement (SHELX $76^{22}$ ) of a scale factor, positional and anisotropic thermal parameters of the non-hydrogen atoms, and positional and isotropic thermal parameters of hydrogen atoms converged to $R=0.067$ and $R_{w}=0.082$. The function minimized in the least-squares refinement was $\sum\left(w\left|F_{0}\right|-\left|F_{\mathrm{c}}\right|\right)^{2}$ where $w=k / \sigma^{2}\left|F_{0}\right|+g\left|F_{0}\right|^{2}$ with $k=1.3582$ and $g=0.00171$. A few hydrogens were kept fixed in the penultimate cycles of refinement with isotropic temperature factors corresponding to the non-hydrogen atoms to which it is attached. The final difference map was featureless. Atomic scattering factors were taken from ref. 23. The scattering factors of chlorine were corrected for anomalous dispersion $\left(\Delta f^{\prime}=0.1 ; \Delta f^{\prime \prime}=0.2\right){ }^{24}$ Illustrations were made by ORTEP ${ }^{25}$ and PLUTO. ${ }^{26}$

\section{References}

1 (a) D. Döpp, Chem. Ber., 1971, 104, 1035, 1043; (b) D. Döpp and E. Brugger, Liebigs Ann. Chem., 1979, 554; (c) D. Döpp, Tetrahedron Lett., 1971, 2757 and unpublished results.

2 D. Döpp and K.-H. Sailer, (a) Tetrahedron Lett., 1975, 1129; (b) Chem. Ber., 1975, 108, 3483.

$3 \mathrm{~K}$. Padmanabhan, D. Döpp, K. Venkatesan, and V. Ramamurthy, $J$. Chem. Soc., Perkin Trans. 2, 1987. 897.

4 E. S. Lewis, Top. Curr. Chem., 1978, 74, 31.

5 (a) H. E. Zimmerman and D. I. Shuster, J. Am. Chem. Soc., 1962, 84, 4527; (b) H. E. Zimmerman, Adv. Photochem., 1963, 1, 183.

6 P. J. Wagner, Top. Curr. Chem., 1976, 66, 1.

7 S. Ariel, V. Ramamurthy, J. R. Scheffer, and J. Trotter, J. Am. Chem. Soc., 1983, 105, 6959.

8 P. J. Wagner, B. P. Giri, J. C. Scaiano, D. L. Ward, E. Gabe, and F. L. Lee, J. Am. Chem. Soc., 1985, 107, 5483.

9 G. Quinkert, T. Tabata, E. A. J. Hickman, and W. Dobrat, Angew. Chem., Int. Ed. Engl., 1971, 10, 198.

$10 \mathrm{~K}$. N. Trueblood, 1982, personal communication.

11 P. Pulay, G. Forgarasi, and J. E. Goggs, J. Chem. Phys., 1981, 74, 3999.

12 W. Van Havers, A. T. H. Lenstra, and H. J. Geise, Acta Crystallogr., 1982, B38, 3119.

13 (a) A. T. H. Lenstra and G. H. Petit, Cryst. Struct. Commun., 1980, 9 , 725; (b) W. Van Haverse, A. T. H. Lestra, H. J. Geise, G. R. Van den Berg, and H. P. Benschop, Acta Crystallogr., 1982, B38, 1635.

14 A. Domenicano, A. Vaciago, and C. A. Coulson, Acta Crystallogr., 1975, B31, 221.

15 'Molecular Structures and Dimensions,' Ultrecht, Oosthock, 1972, vol. A1, p. 52.

16 'International Tables for $X$-Ray Crystallography,' Kynoch Press, Birmingham, 1968, vol. III.

17 O. Hassel and K. O. Strome, Acta Chem. Scand., 1959, 13, 1781.

18 R. E. Bruns, J. Mol. Struct., 1977, 36, 121.

19 W. T. Smith and J. T. Sellas, Org. Synth., 1963, Coll. Vol. IV, 702.

20 C. G. Hatchard and C. A. Parker, Proc. R. Soc. (London), 1956, A235, 518.

21 P. Main, S. J. Fiske, S. E. Hull, L. Lessinger, G. Germain, J. P. Declercq, and M. M. Woolfson, A System of Computer Programs for the Automatic Solution of Crystal Structures from $X$-Ray Diffraction Data. Universities of York, and Louvain, 1980.

22 G. M. Sheldrick, SHELX 76. Program for Crystal Structure Determination, University of Cambridge, 1976.

23 'International Tables for $X$-Ray Crystallography,' Kynoch Press, Birmingham, 1974, vol. IV.

24 D. T. Cromer and D. Liberman, J. Chem. Phys., 1970, 53, 1891

25 C. K. Johnson, ORTEP II, Report ORNL-5138. Oak Ridge National Laboratory, 1976.

26 W. D. S. Motherwell and W. Klegg, PLUTO. Program for the Production of Crystal and Molecular Illustrations. Crystallographic Data Centre, Cambridge, 1978. 